Supporting Information for the paper with title:

\title{
Analysis and implications of structural complexity in low lattice thermal conductivity high thermoelectric performance $\mathrm{PbTe}-\mathrm{PbSnS}_{2}$ composites
}

Chrysoula Ioannidou, Christos B. Lioutas, Nikolaos Frangis, Steven N. Girard, Mercouri G. Kanatzidis 
Figure S.I. 1

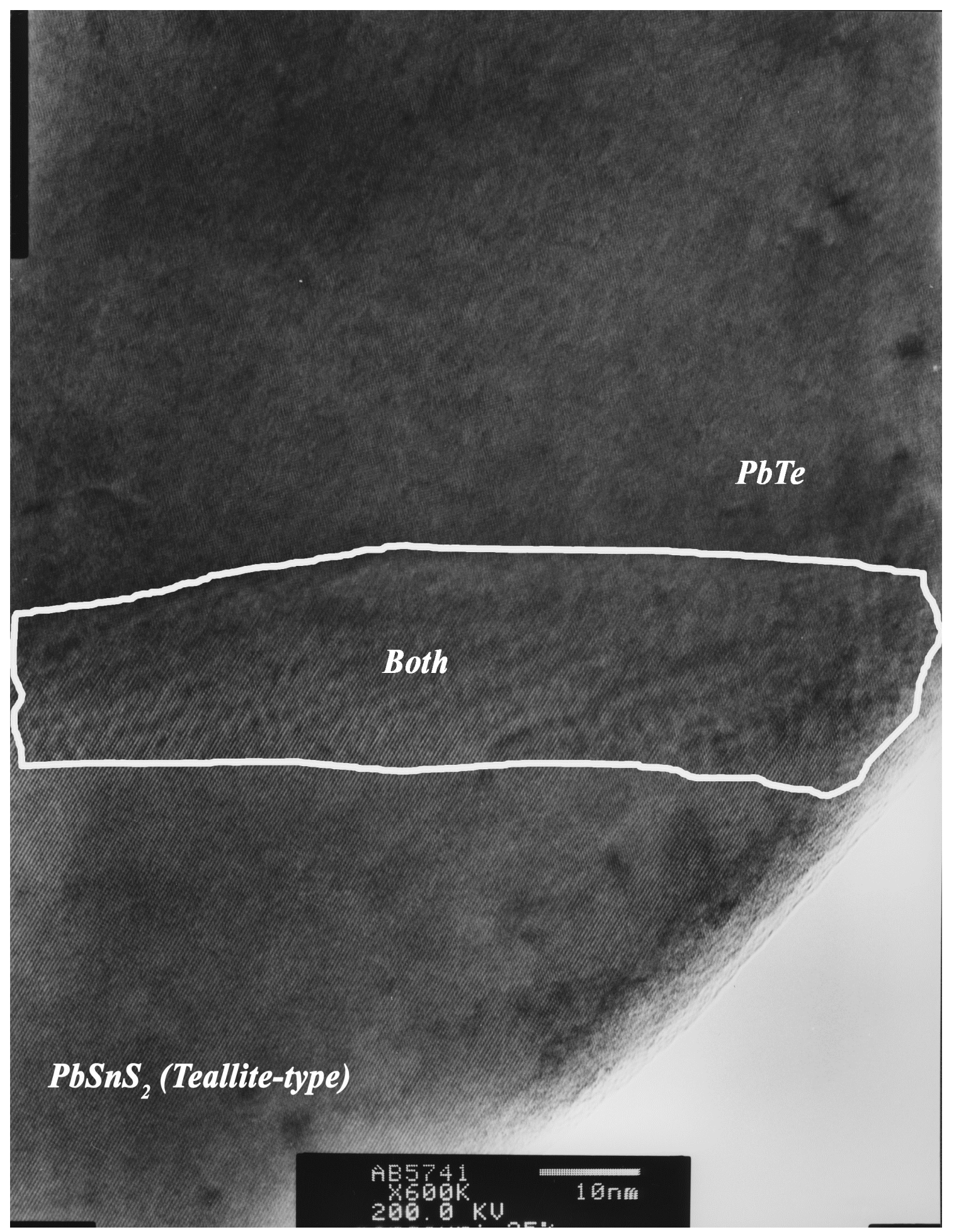

HRTEM image from the interface between $\mathrm{PbTe}$ (matrix) and $\mathrm{PbSnS} 2$ showing the endotaxial growth of the $\mathrm{PbSnS} 2$ crystals. The interface is inclined respect to the direction of the electron beam, giving en extended overlapping area. 
Figure S.I. 2

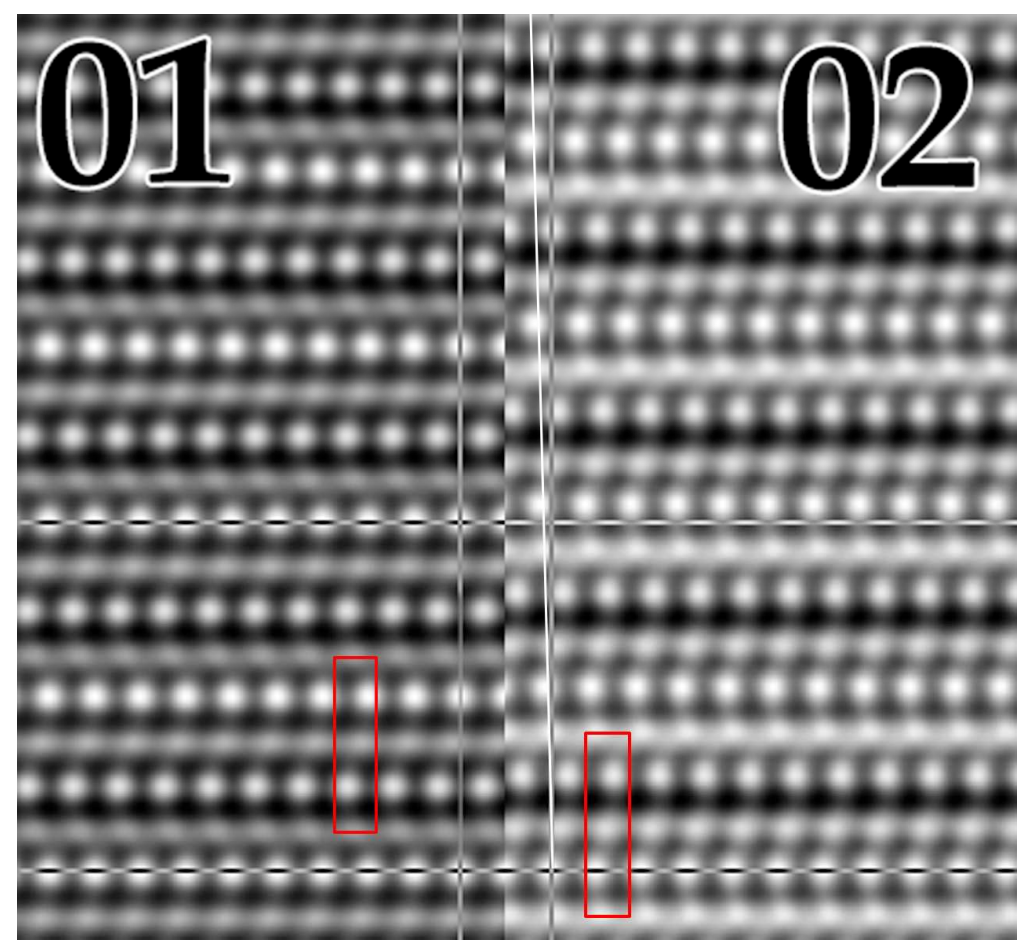

Composite Figure with the averaged images starting with a common line of white dots at the bottom of the picture. That makes clear the deviations in the area 02: (a) the inclination of the angle (white line) and (b) the enlargement of the c axis (shifting of the white dots at the right part of the image). The unit cells are indicated by red rectangles. 
Figure S.I. 3

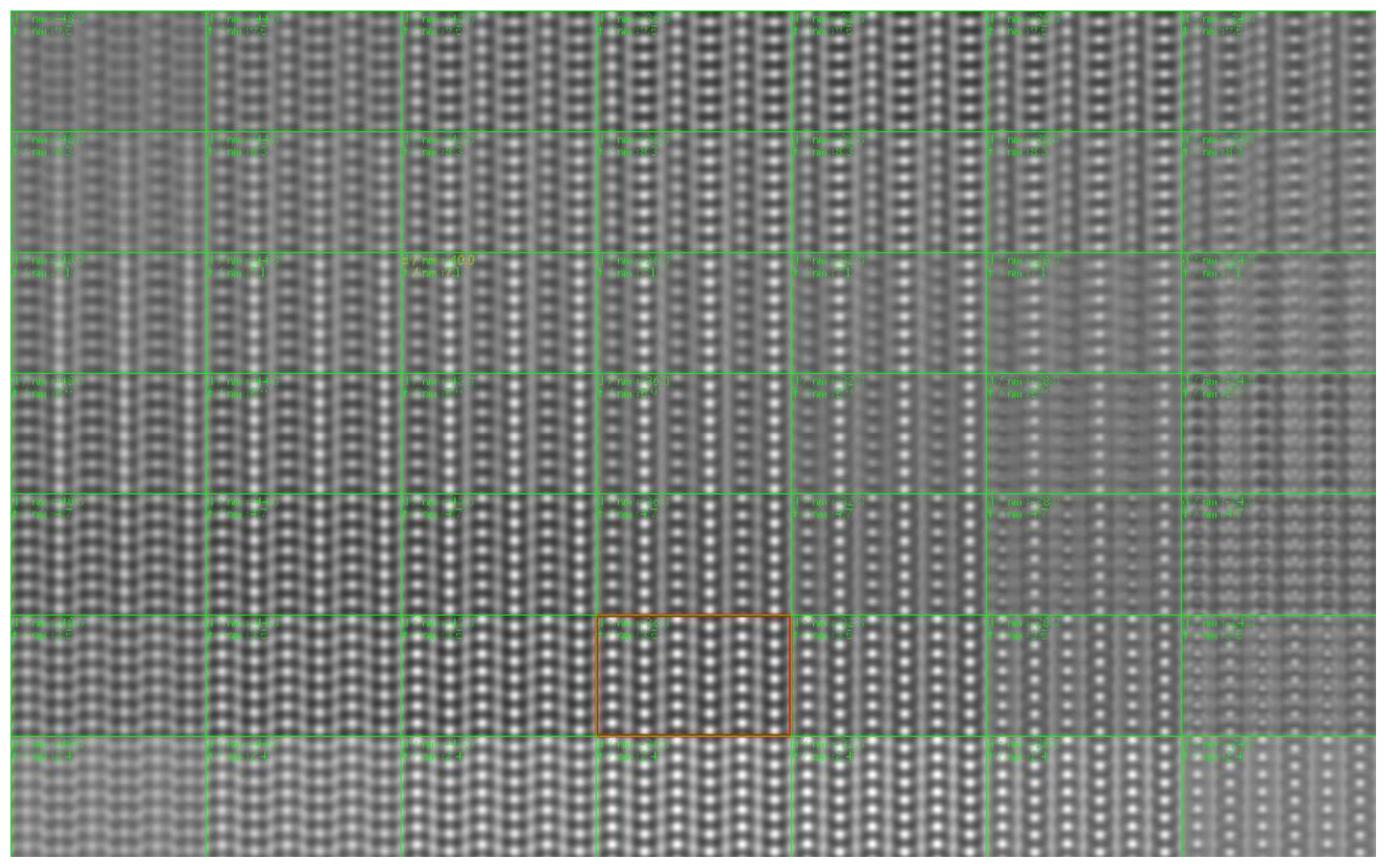

Thickness - defocus matrix. HRTEM image simulation results for the model B. The used image in figure 9a is indicated by red frame. 
Figure S.I. 3

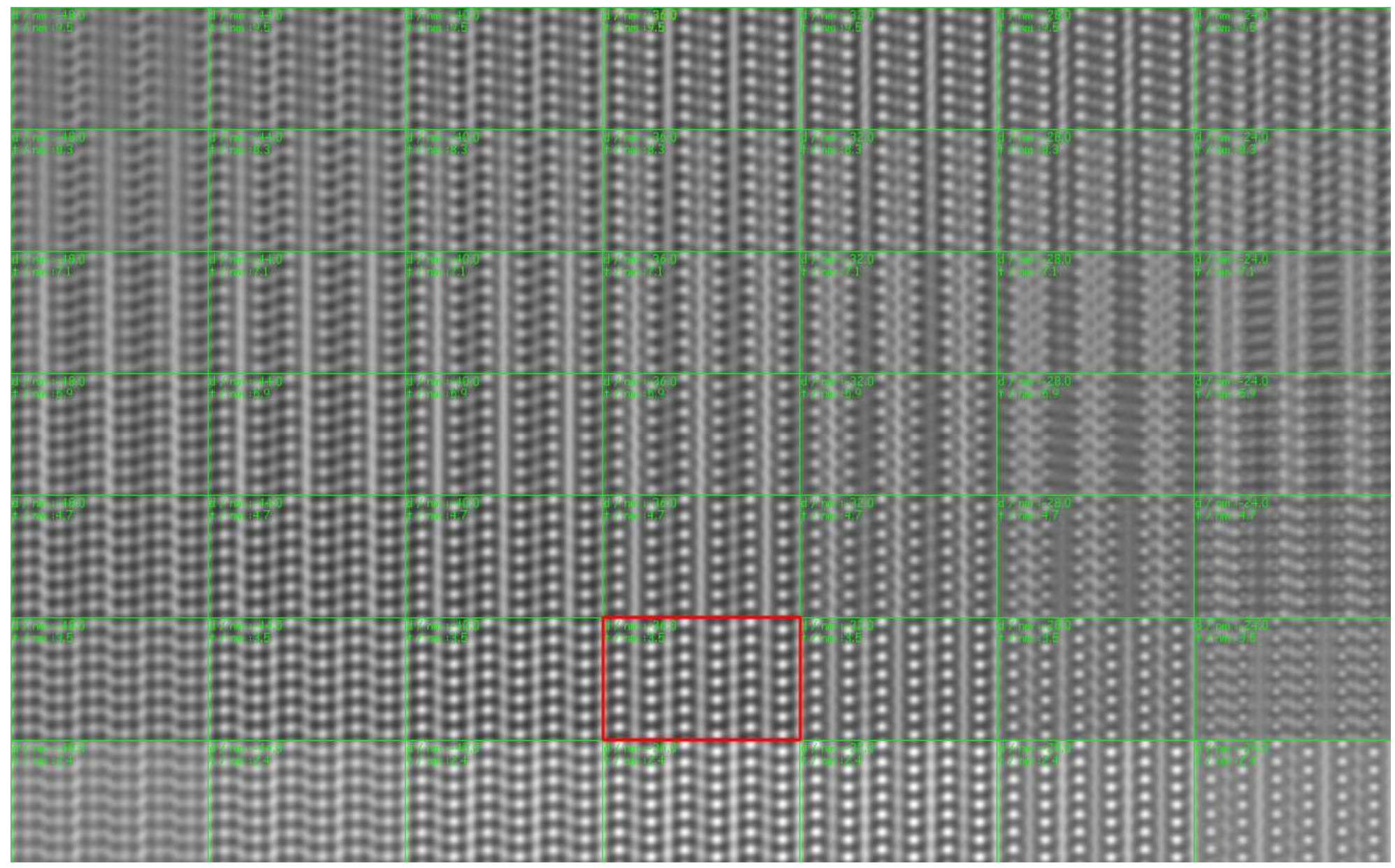

Thickness - defocus matrix. HRTEM image simulation results for the model $\mathrm{C}$. The used image in figure $9 \mathrm{~b}$ is indicated by red frame. 